\title{
IMAGEM E VIOLÊNCIA a perda do presente
}

\author{
Norval Baitello Junior \\ Diretor da Faculdade de Comunicação e Filosofia, \\ Coordenador do Centro Interdisciplinar de Pesquisas em Semiótica da Cultura e da Mídia da PUC-SP
}

\begin{abstract}
Je näher man ein Wort ansieht
desto ferner blickt es zurück.

(Quanto mais de perto se vê uma palavra,

tanto mais de longe ela olhará de volta.)
\end{abstract}

Karl Kraus

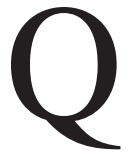

uando o antropólogo e anatomista Ashley Montagu escreveu seu indispensável livro Touching, The Human Significance of The Skin (1971), estabeleceu um marco sobre o estudo dos sentidos (e, por conseguinte, sobre os estudos da comunicação humana), evidenciando a essencialidade dos sentidos de proximidade (tato, olfato, paladar), a contrapelo das tendências da chamada moderna comunicação, que vem se desenvolvendo cada vez mais baseada nos sentidos de distância (a audição e, sobretudo, a visão). Os sentidos da proximidade, em particular o sentido do tato, têm sido considerados toscos e, quando muito, auxiliares menores do conhecimento racional. As linguagens do tato e a comunicação tátil circunscreveram-se a áreas de refúgio, sendo desenvolvidas apenas quando da perda da visão ou então como terapias específicas, destinadas a excepcionalidades patológicas. Assim, pode-se dizer, em resumo, que a comunicação tátil termina sendo prescrita como um tipo de "remédio", sendo raramente vista como normalidade integrante de um sistema comunicativo complexo, composto de diversos aparatos produtores e receptores de linguagens. Montagu afirma que a estimulação tátil, por exemplo, das contrações do trabalho de parto dos mamíferos, é fundamental para "ativar alguns sistemas de manutenção, como o geniturinário e o gastrointestinal e, em parte, o respiratório" (Montagu, 1988:70).

Aponta ainda o traço característico de algumas culturas de cultivar a distância e criar bloqueios culturais contra a proximidade, sobretudo contra o toque, a carícia e o contato corporal, demonstrando o que se perde e o que pode ser lesado na capacidade humana de se comunicar e até mesmo no desenvolvimento saudável do indivíduo, do grupo familiar e da sociedade. O estudo de Montagu se apresenta como uma das grandes contribuições para a compreensão de determinados aspectos da sociabilidade humana e, conseqüentemente, de sua comunicação, inclusive em seus aspectos patológicos, como nos casos de violência.

\section{PROXIMIDADE VERSUS DISTÂNCIA}

Baseando-se na classificação criada pelo cientista político alemão Harry Pross (1972), que divide a mídia em três grandes grupos - primário, secundário e terciário -, de acordo com a complexidade da mediação por aparatos, Vicente Romano, jornalista e comunicólogo espanhol, propõe que:

"El predominio actual de los medios terciarios en la sociedad tecnificada de comunicaciones mediadas pone de manifiesto la falta y la necesidad de la comunicación elemental humana. Aunque se alzan algunas voces, en particular desde la perspectiva de la psicología social, que reclaman la necesidad de esta comunicación personal, no mediada, son muy escasos los estudios de los medios primarios" (Romano, 1993:67). 
De fato, a mídia primária, que se resume ao corpo e suas linguagens naturais, tem estado em baixa diante do poder econômico e político da comunicação em grandes escalas exercido por aparatos cada vez mais potentes e sofisticados. E, ao contrário do que se esperava, a crescente eletrificação das comunicações não ampliou o espaço nem o tempo das relações de proximidade. Mães e pais têm menos tempo para seus filhos e para seus amigos. Pequenas esferas de contato elementar, o bate-papo, a prática esportiva, a prática lúdica têm perdido sistematicamente terreno para a diversão chamada eletrônica, mediada por aparelhos, de comunicação, sim, mas criadores de distância. Até mesmo no processo educacional, caminham céleres as formas de desmanche da proximidade e do convívio direto, nos processos adequadamente denominados "educação a distância". As universidades passam a transferir o espaço-tempo da aula para o chamado "espaço virtual" das redes, os professores são convidados a permanecer o maior tempo possível em suas casas, transformando seu computador em sala de aula e atendimento virtual.

Tal visão mantém pontos de contato com os fatos apontados por Montagu, revelando ambas um ponto de questionamento crítico quanto à hipertrofia dos sentidos de distância em detrimento dos sentidos de proximidade. Tal desequilíbrio pode estar gerando um tipo de carência e suas conseqüentes lesões sociais. Sobre estas lesões, das quais o fenômeno da moderna violência urbana (incluindo-se aí também a violência doméstica) faz parte, já se teceram muitas considerações, sobretudo a respeito de suas raízes socioeconômicas. O que pouco se considerou foi o fenômeno da violência do ponto de vista de suas raízes, por assim dizer, comunicacionais, em outras palavras, como e por que desenvolve-se uma tipologia de códigos comunicativos da violência, e se estes códigos têm a ver com a crescente perda da proximidade. É, pois, sobre esta dimensão que têm trabalhado autores como Harry Pross, em La violencia de los símbolos sociales, Vicente Romano em El tiempo y el espacio en la comunicación, Dietmar Kamper em Bildstörungen (Distúrbios da imagem) e Im Souterrain der Bilder (No subterrâneo das imagens). Estes autores, de certo modo, pensam em consonância, expandem e dialogam com algumas idéias já propostas por Walter Benjamin.

\section{NARRATIVA E CURA}

O subtítulo acima é emprestado justamente de Walter Benjamin, que o forjou para denominar uma de suas peque- nas jóias, minitextos de rara beleza e concisão. "Erzählung und Heilung" (Narrativa e Cura) é um de seus "Denkbilder" (imagens do pensamento, imagens mentais) (Benjamin IV1, 1980:430). ${ }^{1}$ Nele, o autor tece considerações sobre o contar histórias para uma criança doente e os efeitos dessa narrativa:

"Eu o intuía quando N. me disse do poder de cura que teriam as mãos de sua mulher (...) Também se sabe como a narrativa que o doente faz ao médico no começo do tratamento pode tornar-se o início de um processo de cura (...) Não seria porventura curável toda doença, se não se a deixasse jangadear para suficientemente longe - até a desembocadura - no fluxo da narrativa. Considere-se como a dor é um dique que resiste à corredeira da narrativa, então se verá com clareza que ele será rompido onde o declive seja forte, levando tudo o que encontrar em seu caminho para o mar do feliz esquecimento. O acariciar desenha um leito para esta corredeira."

Novamente aparece aqui a referência aos processos comunicativos de proximidade, nos quais mãos e palavras se unem em gestos de aproximação e intimidade. Fluxo de voz e calor de mãos, ambos produzem tatilidades, massageiam. Não seria esta imagem onírica de Benjamin um aspecto de sua reflexão sobre a perda da "aura", definida pelo filósofo como "aparição única de uma distância por mais perto que ela possa estar" (einmalige Escheinung einer Ferne, so nah sie sein mag)" (Benjamin, 1980:480)? A temática da imagem, tão cara ao pensador, não estaria aí presente? Segundo Benjamin, a imagem (da obra de arte) perderia, com o advento da reprodutibilidade técnica, seu valor de culto e ganharia um novo valor, o de exposição. O valor de culto é aquele que cria distância entre o espectador e a imagem, enquanto o valor de exposição deveria criar proximidade e tatilidade. Talvez Benjamin não tivesse vivido o suficiente (ou, por ironia e desgraça, talvez tivesse vivido apenas o suficiente!) para experimentar o poder destrutivo e a violência das imagens inflacionadas - a "estetização da política", em suas próprias palavras - contra as quais ele tanto alertara. A expressão benjaminiana de "estetização da política" traduz exatamente o processo de utilização indiscriminada de imagens para fins de redução do horizonte perceptivo do homem comum. Assim, as imagens não foram propriamente inflacionadas pela reprodutibilidade técnica, mas pela idolatria aos deuses implacáveis que se escondiam em seus subterrâneos, os deuses que comandam, nos bastidores, a asséptica primazia da grande escala e da automação (e todos seus desdobra- 
mentos), os mesmos deuses restauradores da distância como imperativo.

\section{A TIPOLOGIA DA VIOLÊNCIA}

Certamente seria leviano acusar os modernos meios de comunicação de ser responsáveis únicos ou até mesmo majoritários pela violência. O fenômeno da violência é mais amplo e mais profundo do que a faixa de atuação da chamada mídia. No entanto, como a comunicação e seus processos também são mais amplos do que aqueles processos iniciados com a prensa móvel ou com a transmissão de sinais por eletricidade ou por ondas, pode-se considerar bastante plausível a hipótese de interferência dos modernos meios sobre a evolução da capacidade natural de comunicação do homem e também sua contribuição para o desenvolvimento de patologias da comunicação geradoras de violência.

Johan Galtung define violência como “(...) todo ataque evitável contra as necessidades humanas básicas e contra a vida em geral. Por meio da violência as possibilidades de satisfação das necessidades são minimizadas e mantidas sob pressão em um baixo nível. Como violência contam também as ameaças de violência" (Galtung, 1997:913).

Galtung classifica ainda quatro tipos de "violência direta" e quatro tipos de "violência indireta ou estrutural", respectivamente contra a sobrevivência, o bem-estar, a identidade e a liberdade. Enfatiza ainda que "estruturas de violência deixam rastros não apenas no corpo, mas também no pensamento".

Tomemos aqui apenas aquilo que denomina "violência contra a identidade", quando direta, que se manifesta nos processos de "dessocialização, ressocialização e [geração de] cidadãos de segunda classe" e, quando indireta ou estrutural, manifesta-se naquilo que Galtung chama de "penetração" e "normização". Por "penetração" entende os fenômenos nos quais "o favorecido (Begünstigter) abre um espaço no desfavorecido (Benachteiligter)" e por "normização" entende o processo no qual "ao desfavorecido se possibilita apenas uma visão limitada sobre as coisas" (Galtung, 1997:916).

A classificação de Galtung, ampla e profunda, requer reflexão mais detida e cuidadosa. Vamos nos ater, porém, a apenas uma de suas categorias, justamente à "violência estrutural contra a identidade", chamada "normização", e ainda considerando que o veículo utilizado pela normização será aquele que Karl Kraus denomina "Wort" (palavra) e Kamper denomina "Bild" (imagem). Ambos têm suas razões no recorte que fazem, visto que operam com o resíduo simbólico de seus recortes. A distribuição de símbolos e imagens, seja ela feita pelos códigos da visualidade ou por outros códigos, cria grandes complexos de vínculos comunicativos - grupos, tribos, seitas, crenças, sociedades, culturas - e, com isto, cria realidades que não apenas podem interferir na vida das pessoas, como de fato determinam seus destinos, moldam sua percepção, impõem-lhes restrições, definem recortes e janelas para o seu mundo.

\section{A PERDA DA PROPRIOCEPÇÃO}

A propriocepção é o sentido do próprio corpo. Descoberta por Sherrington na década de 1890 , constitui o outro sentido, além de visão, olfato, tato, paladar e audição. O neurologista Oliver Sacks (1988:51-60), em sua narrativa "A dama sem corpo", relata o caso de sua paciente que perdeu a propriocepção e não mais sabia onde estava seu corpo, suas pernas, seus braços, seu tronco, e apenas ficava deitada passivamente sem poder usar as partes que não mais sentia. O distúrbio neurológico da perda da propriocepção é tratado pelo Dr. Sacks por meio do uso da visão como compensação parcial da perda do corpo. Olhar para o corpo, ver onde ele se encontra, possibilita uma consciência indireta e um uso, ainda que restrito, deste. Assim, vendo as pernas e os pés, a paciente conseguia ao menos ficar de pé. Sacks escreve que “(...) o sentido do corpo é dado por três coisas: a visão, os órgãos do equilíbrio (sistema vestibular) e a propriocepção".

A polineurite que provoca a perda da propriocepção constitui uma enfermidade que se descobriu ser bastante freqüente em casos de ingestão de grande quantidades de piridoxina, vitamina $\mathrm{B} 6$.

A perda do corpo, no entanto, não se dá, pelo que parece, apenas nos casos de distúrbios biológicos. Pouco se estudou ainda o fenômeno da perda do corpo causada por fatores sociais e culturais. Talvez a hipertrofia da comunicação pelas imagens, portanto da visão, aliada ao abuso dos sentidos de distância, esteja produzindo um tipo de violência contra a integridade do próprio corpo. Não se poderia indagar se o diálogo entre a visão e a propriocepção não seria também válido na outra direção, ou seja, com tantas imagens, tanta visão, não estaríamos perdendo aos poucos a sensação do próprio corpo, o espaço do eu? Não seria o caso de nos perguntarmos se não estamos também gerando, com isto, uma dificuldade crescente de 
nos colocarmos (e/ou nos sentirmos) no espaço e no tempo que nos cabem no mundo? Isto envolveria a perda do próprio corpo, quer dizer, a perda do aqui e do agora.

\section{A PERDA DO PRESENTE}

Diversos estudiosos têm alertado recentemente para o fenômeno da "perda do presente", uma dificuldade crescente de sentir-se em seu aqui e agora. Dietmar Kamper declarou, em um encontro com publicitários (segundo relato pessoal em janeiro de 1999, em Berlim) que a maior dificuldade do homem contemporâneo é estar em seu tempo. De fato, o tempo presente tem se desdobrado em tantas dimensões e possibilidades que se esgarçou e esvaneceu, oferecendo um sem número de vias de escape e fuga. A inflação das imagens é um dos aspectos desse fenômeno. A impressão de uma natureza transfinita inesgotável e sempre reversível do tempo é outro. O primeiro aspecto traz consigo uma crise no regime da visibilidade, uma vez que toda hipertrofia gera a distrofia compensatória. Quanto mais imagens, menos visibilidade e quanto mais visão, menos propriocepção, o sentido por excelência do aqui e agora. $\mathrm{O}$ segundo traz consigo a perda do presente, pois tantos presentes se superpõem ao mesmo tempo que cada um deles não terá tempo de se tornar ato, apenas remetendo para o outro, subentendendo e exigindo a rápida passagem em zapping para o próximo.

O pesquisador e jornalista Dominik Klenk enxerga o problema da "perda do presente" na natureza mediatizada que vem assumindo o "ser dialógico homem" (Buber), na perda do espaço comunicativo do diálogo interpessoal que confere sentido ao tempo de vida, esse recurso esgotável do homem. Klenk qualifica a crescente invasão da mídia elétrica como monológica e, portanto, destruidora do tempo presente que se constrói no diálogo.

Dietmar Kamper desloca o problema em direção à perda do corpo e confere à problemática da "crise da visibilidade" um lugar de destaque. Em seu livro Unmögliche Gegenwart (Presente impossível) (1995), escreve:

"Espiritualização, aquela antiga ascese do corpo, mudouse na Renascença para a 'figurativização', para a transformação da matéria em imagem. No entanto esta visibilização do invisível meteu-se desde o início do século em uma crise cujos contornos continuam obscuros. Trata-se da tentativa de exonerar o corpo, mas não pela repressão, mas pela substituição: ao invés do corpo humano preferem-se as imagens do corpo" (Kamper, 1995:37). E conclui: "É impossível aumentar o círculo do visível sem que igualmente o invisível se amplie. Quanto mais luz, mais sombra" (Kamper, 1995:57).

Assim, uma imagem nunca será apenas uma presença, mas também uma ausência. Necessário rastrear sensivelmente a violência como sombra das figuras a quem emprestamos o status e o poder de realidade. Para que elas não nos comandem, violentamente.

\section{NOTAS}

E-mail do autor: norval@pucsp.br

1. Traduzido em português como "Conto e cura".

\section{REFERÊNCIAS BIBLIOGRÁFICAS}

BENJAMIN, W. "Erzählung und Heilung”. In: Gesammelte Schriften. Frankfurt/Main, Suhrkamp, v.IV-1, 1980.

“Conto e Cura". In: Obras Escolhidas II. 2a ed. São Paulo, Brasiliense, p.269 (tradução Rubens Rodrigues Torres f. e J. Carlos Martins Barbosa).

Gesammelte Schriften . Frankfurt/Main, Suhrkamp, 1980, v.I-2.

GALTUNG, J. "Gewalt”. In: WULF, Ch. Vom Menschen. Handbuch Historische Anthropologie. Weinheim u. Basel, Beltz, 1997.

KAMPER, D. Bildstörungen. Im Orbit des Imaginären. Ostfildern, Cantz, 1994. . Unmögliche Gegenwart. Zur Theorie der Phantasie. München, W. Fink, 1995. Philo, 1997.

Im Souterrain der Bilder. Die schwarze Madonna. Bodenheim,

KLENK, D. “Gegenwartsverlust” In: Der Kommunikationsgesellschaft. Münster, Lit, 1998.

MONTAGU, A. Touching. The human significance of the skin. New York, Harper \& Row, 1971 (Tocar. O significado humano da pele. São Paulo, Summus, 1988, tradução M. Silvia Mourão Netto)

PROSS, H. Medienforschung. Darmstadt, C. Habel, 1972.

. La violencia de los símbolos sociales. Barcelona, Anthropos, 1989 (tradução Vicente Romano).

ROMANO, V. Desarollo y progreso. Por una ecología de la comunicación. Barcelona, Teide, 1993. Hiru, 1998

El tiempo y el espacio en la comunicación. Hondarribia, Argitalexte

SACKS, O. O homem que confundiu sua mulher com um chapéu. 2a ed. Rio de Janeiro, Imago, 1988 (tradução Talita Macedo Rodrigues). 